The Journal of Vitaminology 13, 89-92 (1967)

\title{
DISCOVERY OF A NEW FLAVIN PHOSPHATE SYNTHETASE WHICH REQUIRES GUANOSINE-5'-TRIPHOSPHATE
}

\author{
SEI TACHIBANA \\ Department of Chemistry, Faculty of Science and Engineering, \\ Ritsumeikan University, Kita-ku, Kyoto
}

(Received September 8, 1966)

It has been reported that a riboflavin cyclic- $2^{\prime}, 5^{\prime}$-monophosphate $\left(\mathrm{FMN}^{\prime}\right)$ synthetase occurs in a $70-80 \%$ saturation fraction of ammonium sulfate of the cell-free extract of Rhizopus oryzae. The enzyme requires guanosine-, inosine-, or uridine5 -triphosphate and some other unknown cofactor, while adenosine- or cytidine$5^{\prime}$-triphosphate is inactive.

The occurrence of a flavin phosphorylating enzyme having such nucleotide specificity that GTP, ITP and UTP are active, but ATP and CTP are inactive, has not hitherto been reported.

\section{EXPERIMENTAL}

\section{Organism and Culture}

Rhizopus oryzae IFO No. 4698 was used in this work.

The mold was grown in a medium containing $3 \mathrm{~g}$ glucose, $0.1 \mathrm{~g} \mathrm{NaNO}_{3}, 0.1 \mathrm{~g}$ $\mathrm{NH}_{4} \mathrm{NO}_{3}, 0.1 \mathrm{~g} \mathrm{K \textrm {K } _ { 2 }} \mathrm{PO}_{4}, 0.05 \mathrm{~g} \mathrm{MgSO}_{4} \cdot 7 \mathrm{H}_{2} \mathrm{O}, 0.05 \mathrm{~g} \mathrm{KCl}, 1 \mathrm{~g} \mathrm{CaCO}$, and $100 \mathrm{ml}$ tap water in a $500 \mathrm{ml}$ Fernbach flask for 7 days at $30^{\circ}$ stationally. Mycelia were harvested, washed, pressed in filter paper layers and dried at room temperature with a fun. The drying was further carried out in r'acuo in $\mathrm{CaCl}_{2}$-desiccator more than two weeks in a cold room.

\section{Preparation of Enzyme Solution}

The dried mycelia were powdered in a homogenizer. Twenty grams of mycelial powder was extracted with some glass powder in $200 \mathrm{ml}$ of $0.05 M$ phosphate buffer $(\mathrm{pH} 5.2)$ in a mortar. The homogenate was centrifuged at $8000 \times g$ for 20 minutes, and $165 \mathrm{ml}$ of the supernatant was obtained. To the supernatant, crystalline $\left(\mathrm{NH}_{4}\right)_{2} \mathrm{SO}_{4}$ was added up to 0.7 saturation, followed by centrifugation at $8000 \times$ $g$ for 30 minutes. To the supernatant, $\left(\mathrm{NH}_{4}\right)_{2} \mathrm{SO}_{4}$ was added up to 0.8 saturation and it was kept for 14 hours at $5^{\circ}$. The precipitate was collected by centrifugation at $8000 \times g$ for 30 minutes and disolved in $3.2 \mathrm{ml}$ of $0.005 \mathrm{M}$ phosphate buffer ( $\mathrm{pH}$ 5.5). One $\mathrm{ml}$ of the enzyme solution was dialysed in Cello-tube against 3 liters of pure water for 16 hours at $5^{\circ}$. The dialysate whose volume increased to $1.3 \mathrm{ml}$ was centrifuged at $15,000 \times g$ for 30 minutes to remove the precipitate and 1 沙花 精. 
kept in a deep freezer for use. The protein concentration was determined to be about $0.18 \%$ by the spectrophotometric method of Warburg and Christian (2).

\section{Preparation of Boiled Cell-free Extract}

One part of dried mycelium powder was extracted with ten-fold $0.05 M$ phosphate buffer ( $\mathrm{pH}$ 5.2), followed by heating for 15 minutes in boiling water. The supernatant obtained by centrifugation at $8000 \times g$ for 20 minutes was kept in a deep freezer to use as a cofactor of $\mathrm{FMN}^{\prime}$ synthetase.

\section{Nucleoside Triphosphates}

ATP, CTP, GTP, ITP, and UTP used without further purification were sodium salts purchased from Sigma Chemical Co. Ltd. of 98-99\% purity.

\section{Riboflavin and Other Reagents}

Riboflavin was a pure product of Takeda Pharmaceutical Industries Ltd., and used without further purification. All other chemicals were of the reagent grade.

\section{Enzyme Reaction}

The reaction mixture contained $1.06 \times 10^{-4} \mathrm{M}$ riboflavin, $5 \times 10^{-3} \mathrm{M}$ nucleoside triphosphate or $0.03 \mathrm{ml}$ boiled cell-free extract, $2 \times 10^{-3} \mathrm{M} \mathrm{MgSO}_{4}, 2 \times 10^{-2} \mathrm{M}$ phosphate buffer (pH 5.5), $0.03 \mathrm{ml}$ enzyme solution and water in a final volume of $0.15 \mathrm{ml}$. After adding $0.05 \mathrm{ml}$ toluene, the reaction mixture was incubated at $37^{\circ}$.

\section{Assay of Reaction Product}

The method of paper electrophoresis of the author (3) was employed to detect FMN'. Paper chromatography with the solvent system of $n$-butanol-acetic acidwater $(4: 1: 5)$ was used, if necessary. The amounts of flavins were determined fluorometrically on a paper strip with Simazu-Kotaki Microphoto-reflecting fluorometer.

\section{RESULTS}

The results of the assay of 16.5 hour-reaction mixture revealed that GTP, ITP or UTP was active for $\mathrm{FMN}^{\prime}$ formation, whereas ATP or CTP was inactive, as shown in Table 1 and Fig. 1. After 72-hour incubation, the amounts of FMN' in the tubes containing GTP, ITP and UTP increased significantly, while ATP and CTP exhibited no effect. The FMN' synthetase was quite different in nucleotide specificity from riboflavin kinase (ATP : riboflavin 5 '-phosphotransferase, EC 2.7.1.26) and other phosphotransferase hitherto obtained from any organism.

TABLE 1

Nucleotide Specificity

\begin{tabular}{lcc}
\hline \hline \multicolumn{1}{c}{ Addition } & & FMN' formed $^{\prime}$ \\
\hline & $M$ & $M$ \\
GTP & $5 \times 10^{-3}$ & $1.1 \times 10^{-5}$ \\
ITP &, & $0.8 \times 10^{-5}$ \\
UTP &, & $0.4 \times 10^{-5}$ \\
ATP &, & 0 \\
CTP & $0.03 \mathrm{ml}$ & 0 \\
Boiled cell-free extract & - & $2.0 \times 10^{-5}$ \\
None & & 0 \\
\hline
\end{tabular}




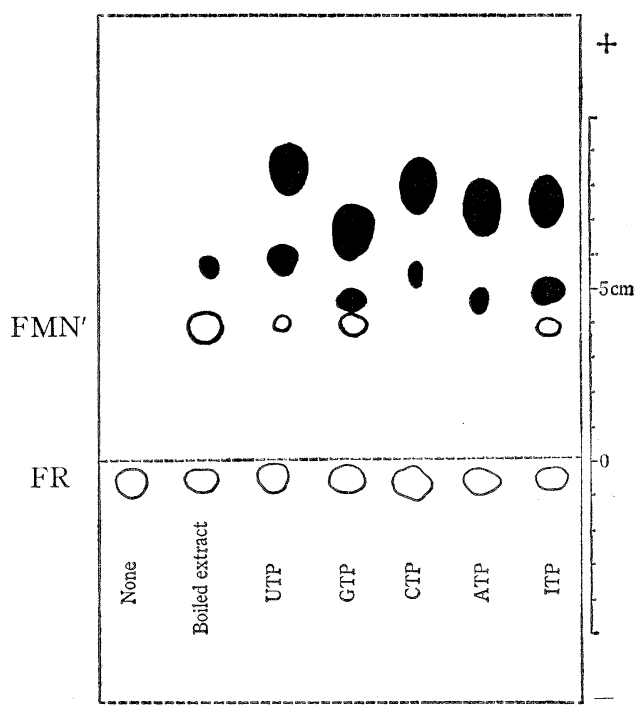

FIG. 1 Paper Electrophoregram

$0.05 M$ phosphate buffer, pH $5.9 ; 200$ volts; 4 hours; spotted in the middle.

While GTP was most active among the five trinucleotides, the effect was inferior to the effect of the boiled cell-free extract which did not show so significant ultraviolet absorbing spots as the other five nucleotides.

\section{DISCUSSION}

It is of interest that the active nucleotide, GTP, ITP or UTP, has 6-hydroxy or 4-oxo structure in purine or pyrimidine moiety, respectively. On the contrary, inactive nucleotide, ATP or CTP, has 6 -amino or 4-amino structure. The contrast between the two may concern the mechanism of formation of $\mathrm{FMN}^{\prime}$. Owing to some interaction between $\mathrm{N}_{1}$ of isoalloxazine and $\mathrm{NH}_{2}$ of ATP or CTP, the phosphate would not be attached to $\mathrm{C}_{2^{\prime}}$ position of the ribityl moiety. Against this, it may be pointed out that in riboflavin kinase detectable in the salting out fraction at $40-50 \%$ ammonium sulfate saturation of the cell-free extract of the mold, the interaction make it possible to attach not at $\mathrm{C}_{2^{\prime}}$, but at $\mathrm{C}_{5^{\prime}}$. It was, therefore, suggested that the position of $\mathrm{NH}_{2}$ being carried on base might play an important role in the selection of the position to be phosphorylated, as shown in Fig. 2.

Moreover, it is another interesting thing to consider the possible function of boiled cell-free extract. It is unlikely that the effect of cell-free extract may consist of only the effect of GTP, ITP or UTP, because the electrophoresis strip of cell-free extract could not exhibit so remarkable UV absorbing spot as GTP, ITP or UTP as shown in Fig. 1.

In the extract there may be some unknown factor which promots the cyclization of phosphate linkage, or may be more effective phosphate donor than GTP. Another possibility is that the extract contain some phosphorylated high polymer 


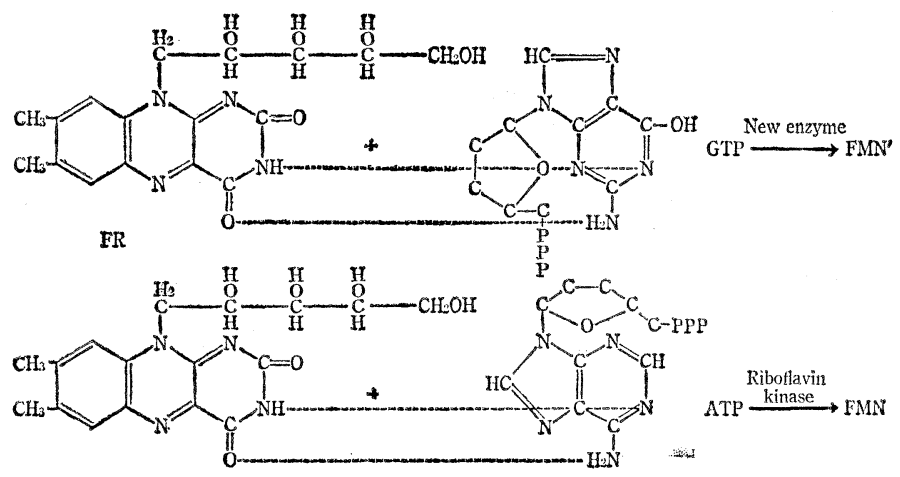

FIG. 2 Possible Mechanisms of New Enzyme and Riboflavin Kinase

to be accelerated by GTP, ITP or UTP. Which possibility will be true remains to be settled by using radio-active phosphate.

Meanwhile, it may be possible to exploit this finding to characterize a flavin cyclic-2', 5'-diphosphate-forming enzyme of Aspergillus oryzae (4).

\section{SUMMARY}

1. The author found a novel enzyme in the salting out fraction by $70-80 \%$ ammonium sulfate saturation of the cell-free extract of Rhizopus oryzae. The enzyme requires GTP, ITP or UTP to produce flavin cyclic- $2^{\prime}, 5^{\prime}$-mononucleotide from riboflavin, whereas ATP or CTP is inactive.

2. The relative efficiency of GTP, ITP and UTP was nearly $10: 8: 4$.

3. The boiled cell-free extract of the mold contains some other unknown factor which stimulate $\mathrm{FMN}^{\prime}$ formation than these nucleotides.

\section{ACKNOWLEDGEMENT}

The excellent technical assistances of Mr. J. Siode and Mr. M. Yokoi are greatly appreciated.

\section{REFERENCES}

1. Tachibana, S., and Tamura, M., Abstract of the 37th Annual Meeting of the Jap. Biochem. Soc., Seikagaku 36, 642 (1964).

2. Warburg, O., and Christian, W., Biochem. Z. 310, 384 (1941).

3. Tachibana, S., Vitamins 22, 291 (1961); J. Vitaminol. 7, 294 (1961).

4. Tachibana, S., and Katagiri, H., Vitamins 8, 309 (1955). 